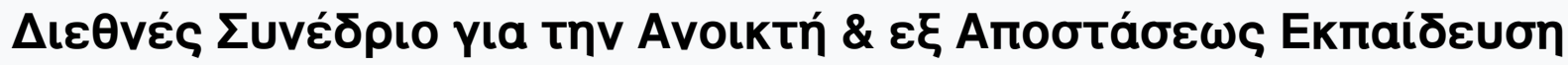

Tóp. 6, Ap. 2B (2011)

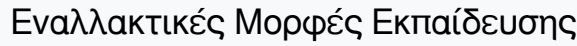

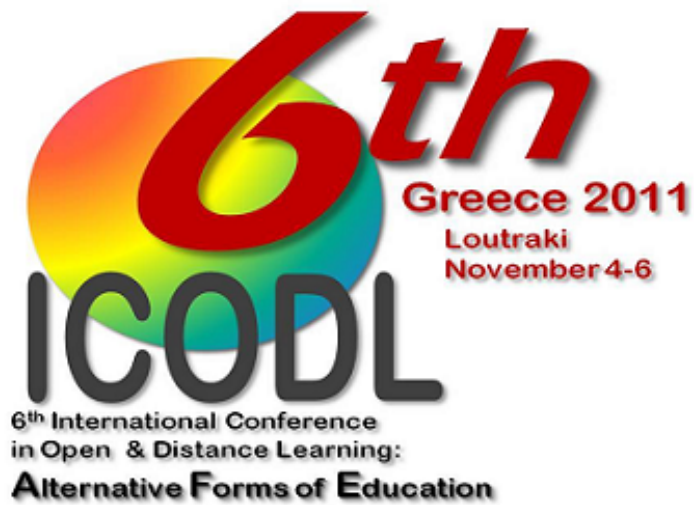

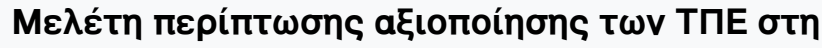

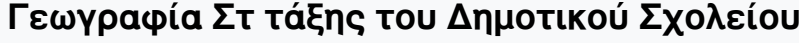

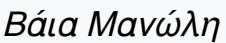

doi: $10.12681 /$ icodl. 653

TOMOE B

PART / MEPOE B 


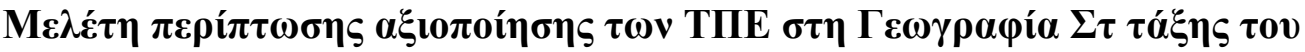

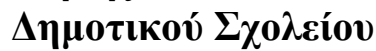

\section{A case study for teaching Geography at the Primary school using ICT}

\author{
Bóı M $\alpha v \omega ́ \lambda \eta$

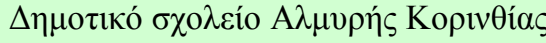 \\ Y $\pi \mathrm{o} \delta \varepsilon v \theta v \dot{v} \tau \rho \imath \alpha$ \\ vamano@otenet.gr
}

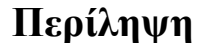

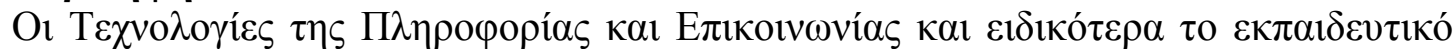

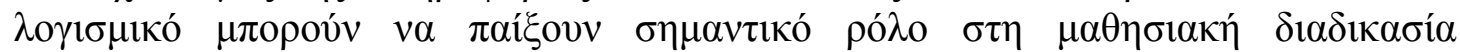

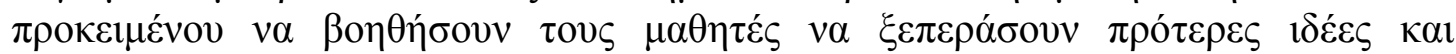

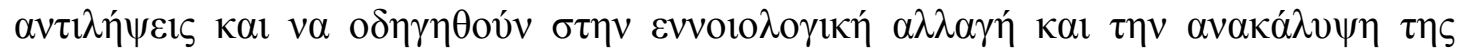

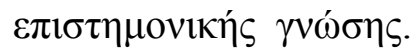

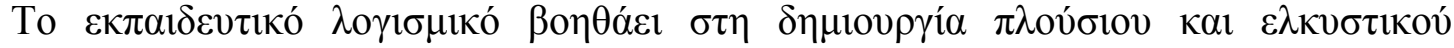

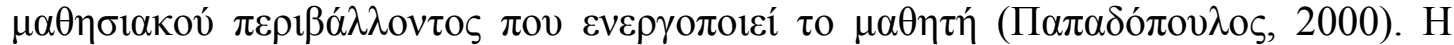

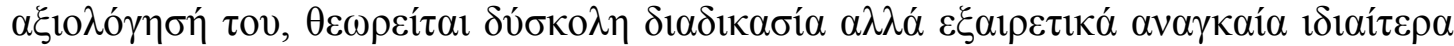

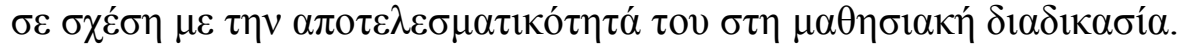

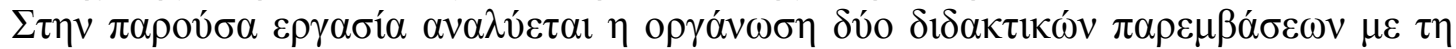

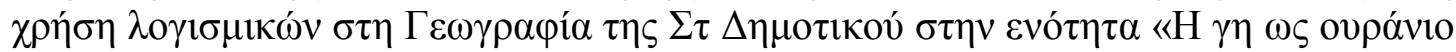

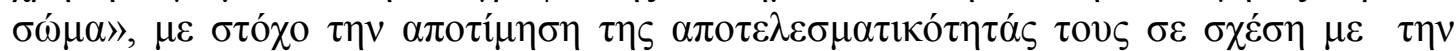

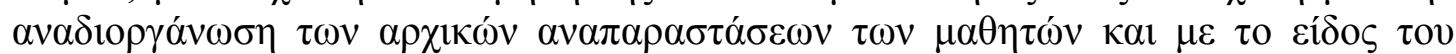

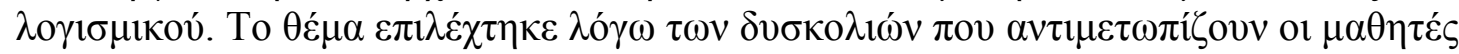

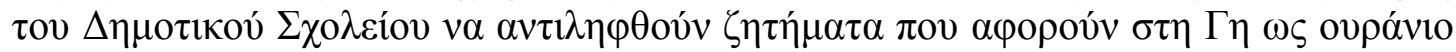

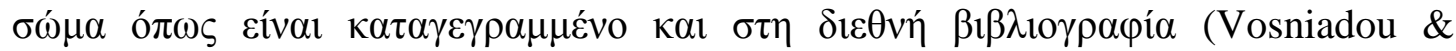

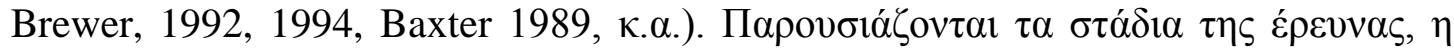

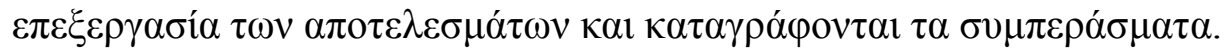

\begin{abstract}
ICT and especially educational software provides as a big challenge for educational process. This paper is a case study for teaching Geography using ICT at $6^{\text {th }}$ grade of Primary school. Two educational softwares are used in order to find out which is most suitable to help students to overcome their misconceptions about Earth as a star in our solar system.
\end{abstract}

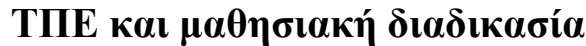

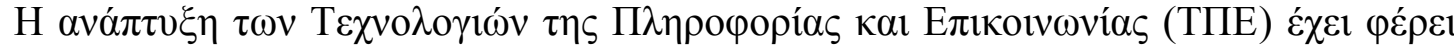

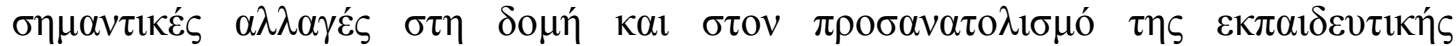

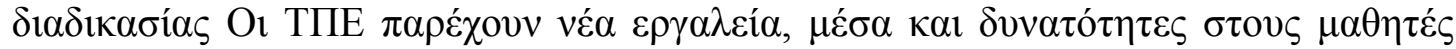

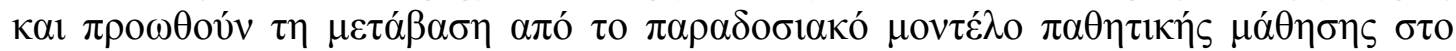

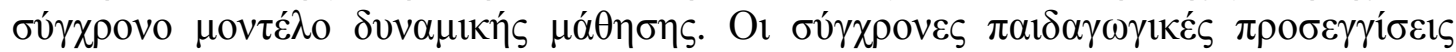

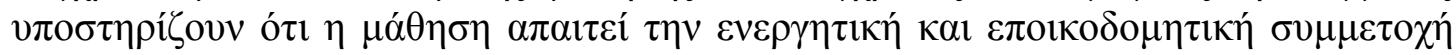

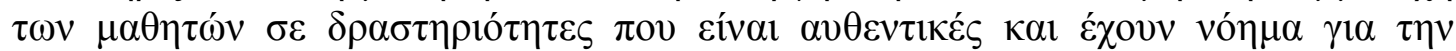

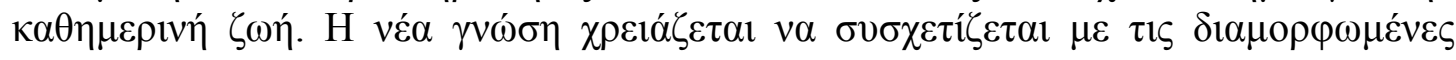




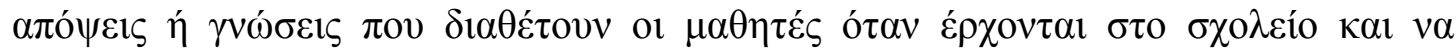

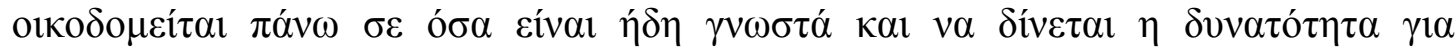

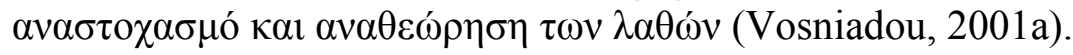

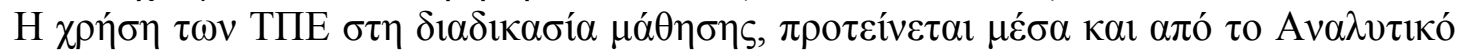

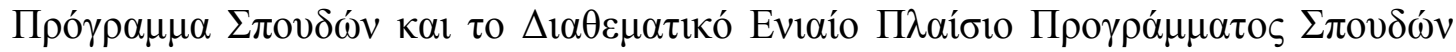

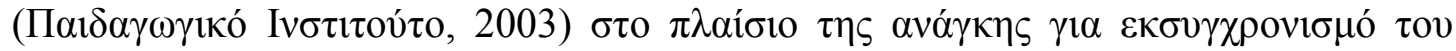

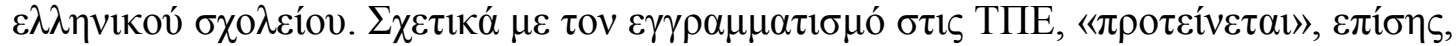

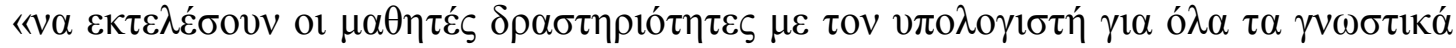

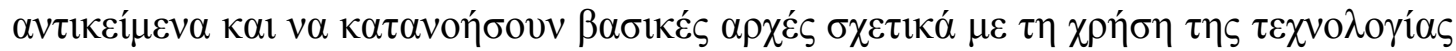

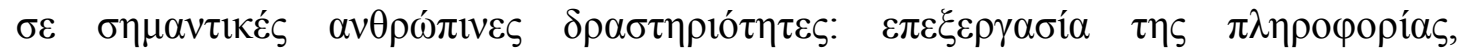

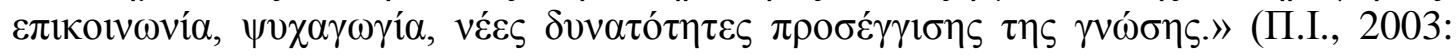

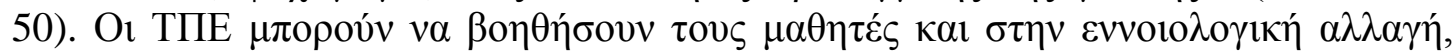

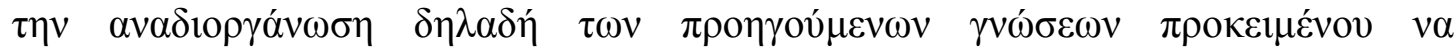

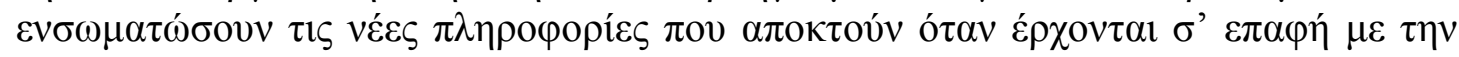

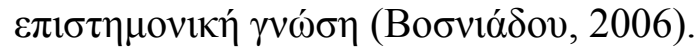

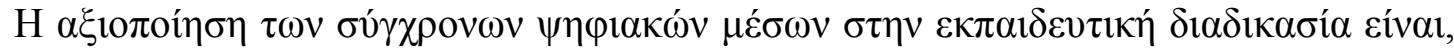

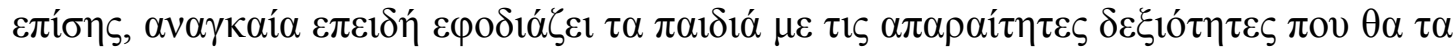

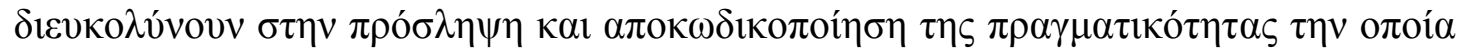

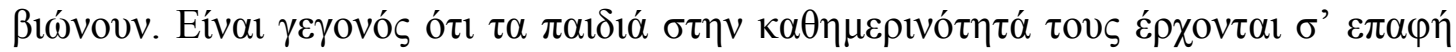

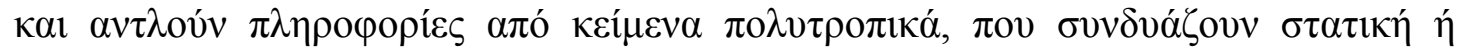

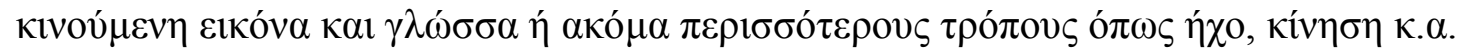

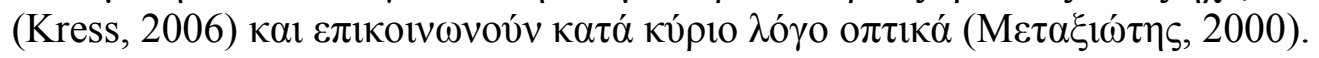

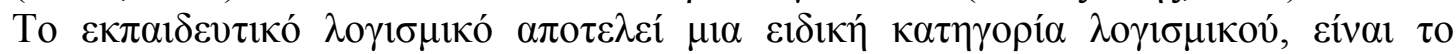

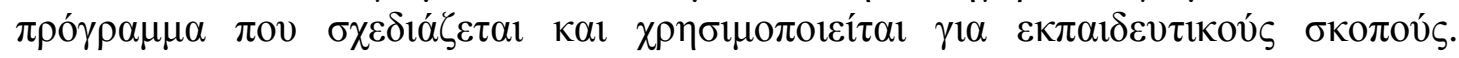

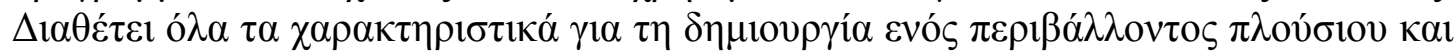

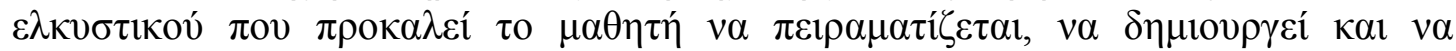

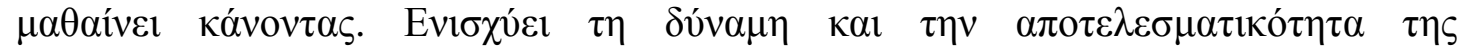

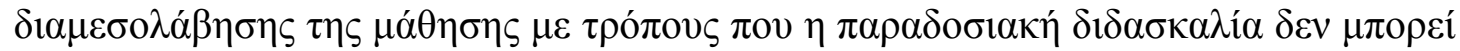

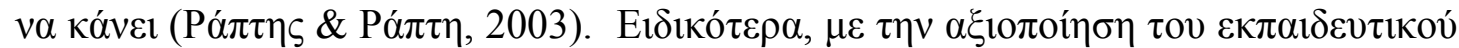

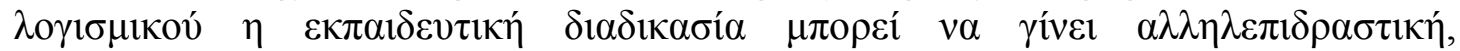

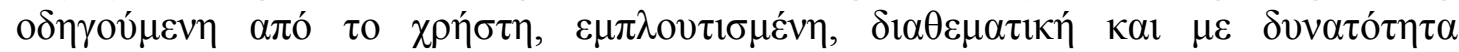

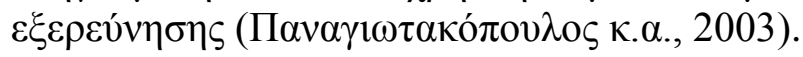

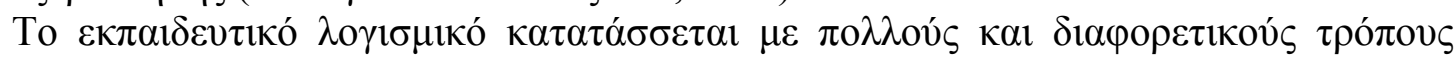

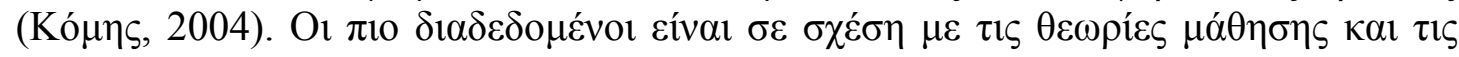

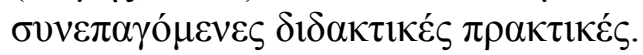

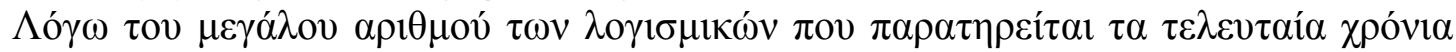

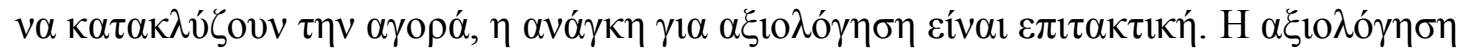

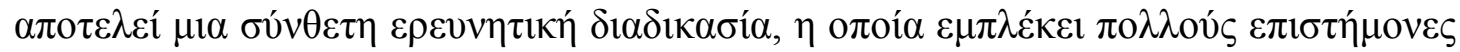

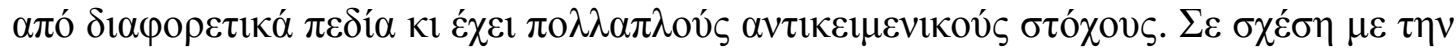

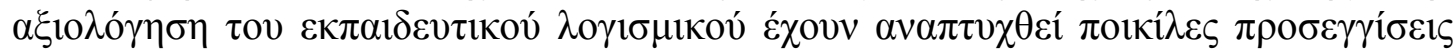

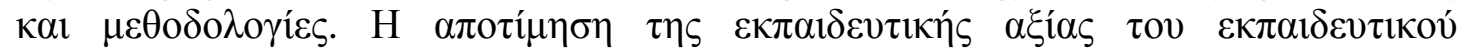

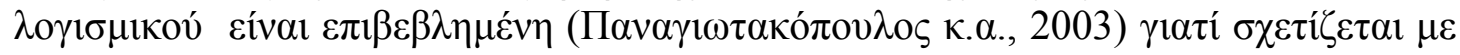

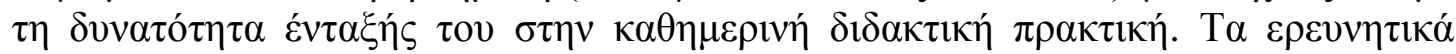

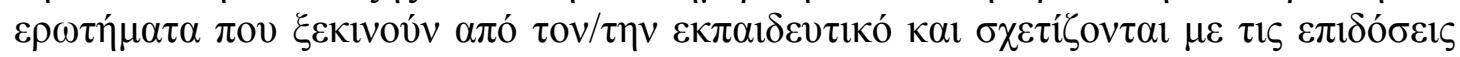

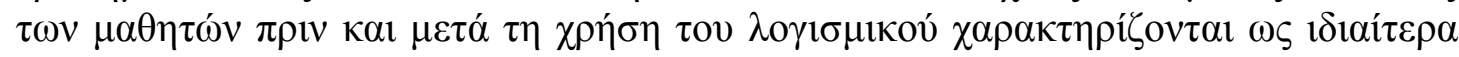

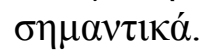

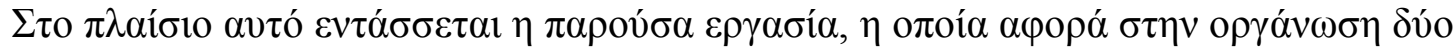

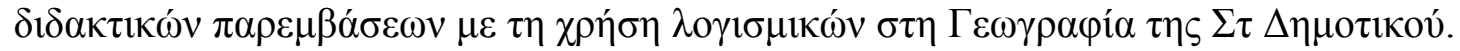

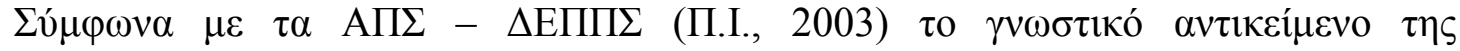

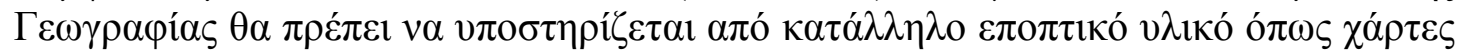




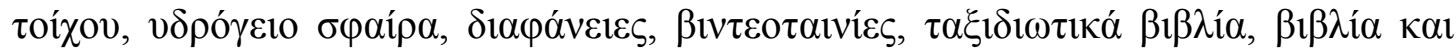

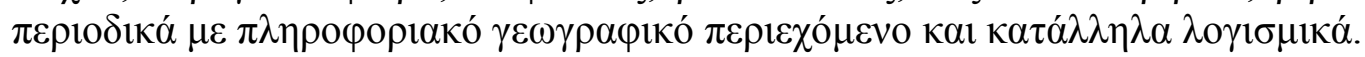

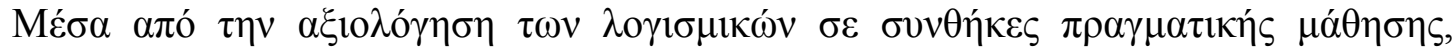

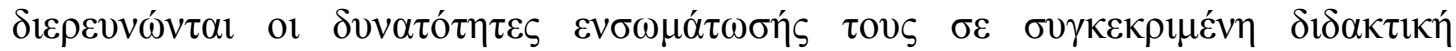

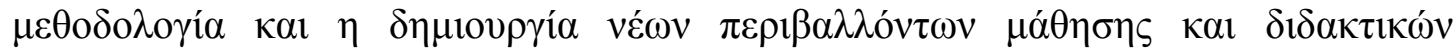

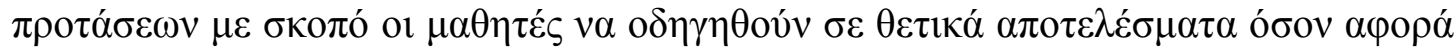

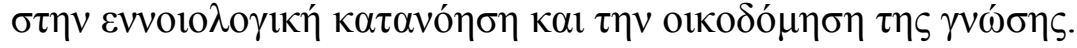

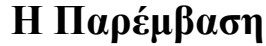

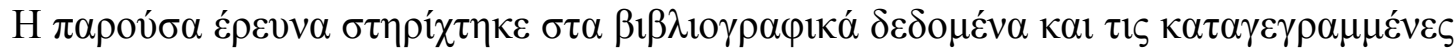

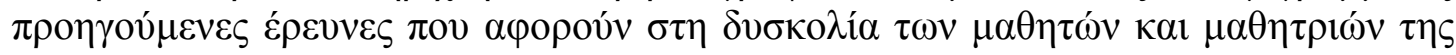

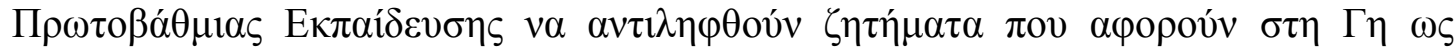

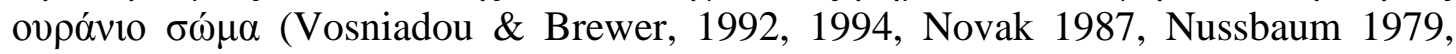

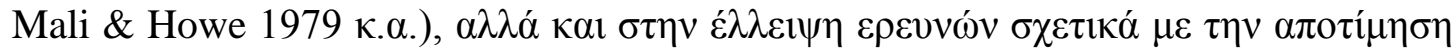

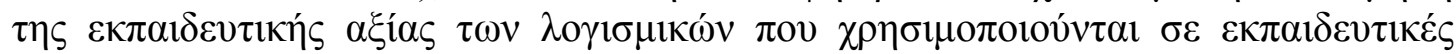
$\pi \alpha \rho \varepsilon \mu \beta \alpha ́ \sigma \varepsilon 1 \zeta$.

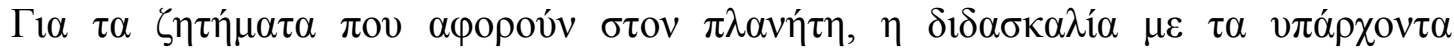

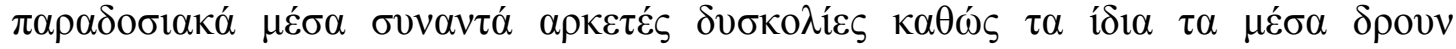

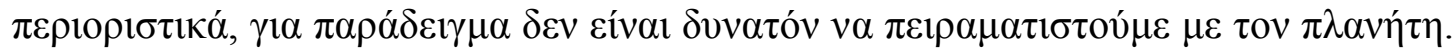

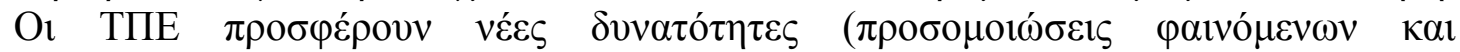

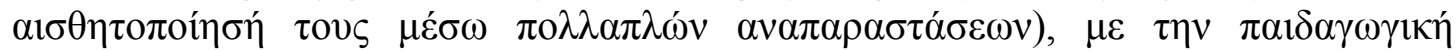

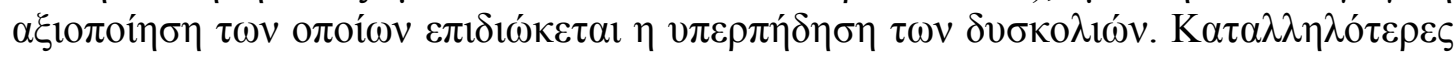

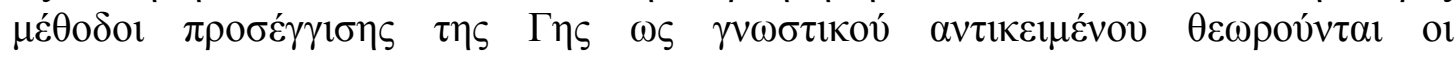

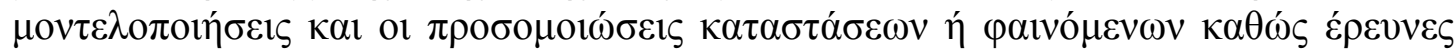

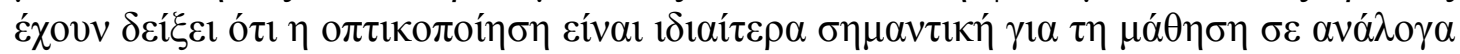

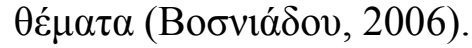

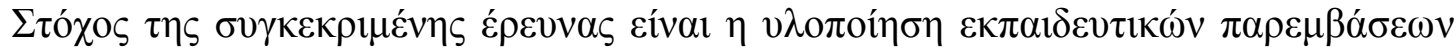

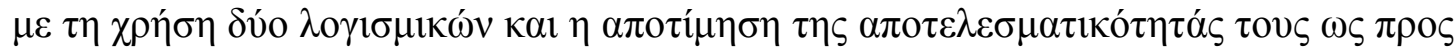

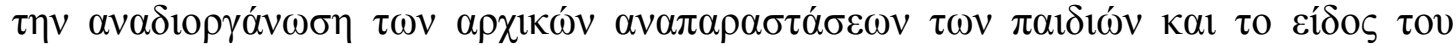

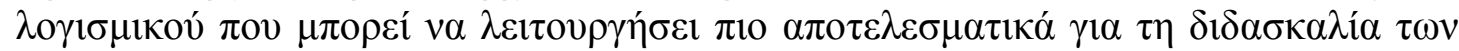

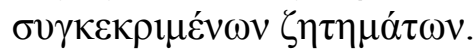

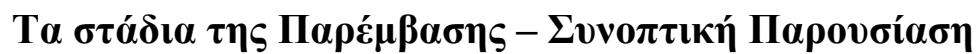

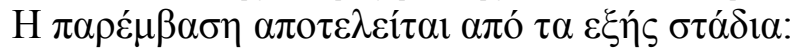

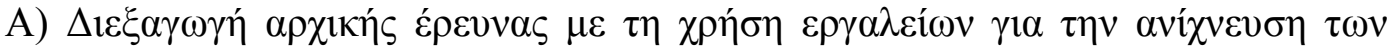

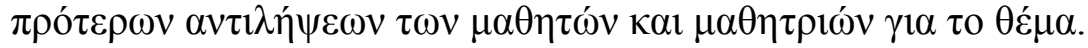

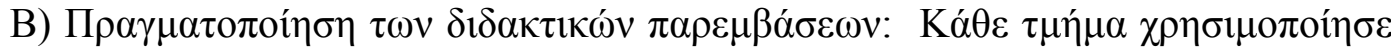

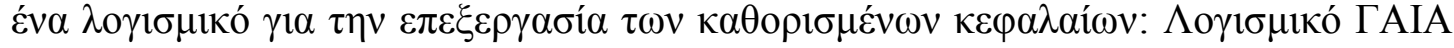

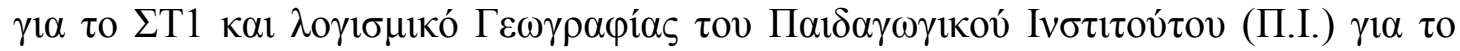

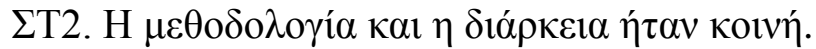

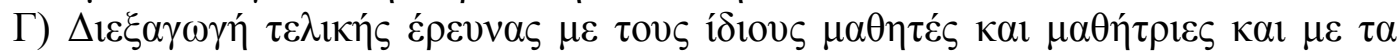

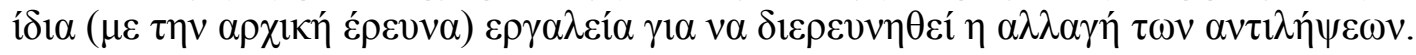

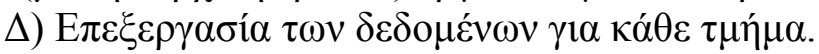

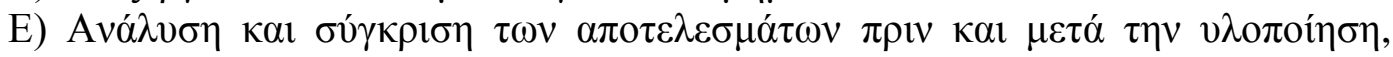
$\alpha \pi \circ \tau i ́ \mu \eta \sigma \eta \tau \eta \varsigma \alpha \pi 0 \tau \varepsilon \lambda \varepsilon \sigma \mu \alpha \tau 1 \kappa o ́ \tau \eta \tau \alpha \varsigma \tau \eta \varsigma \pi \alpha \rho \varepsilon ́ \mu \beta \alpha \sigma \eta \varsigma$.

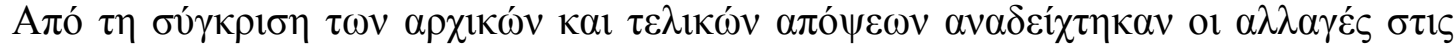

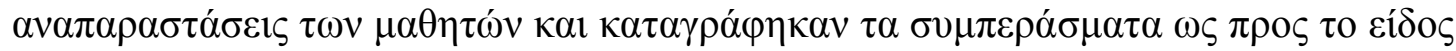

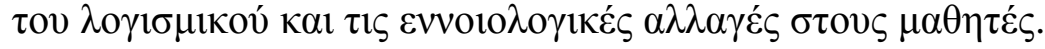

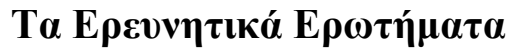




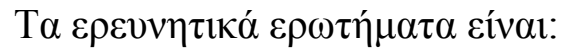

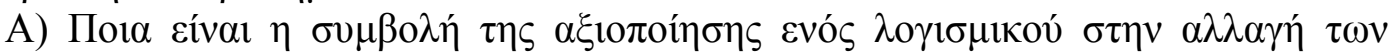

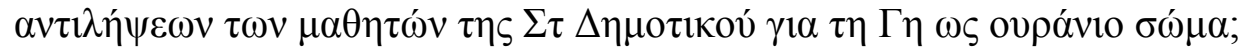

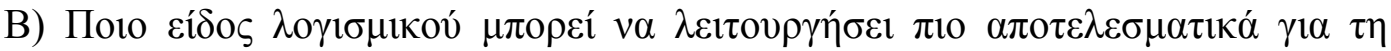

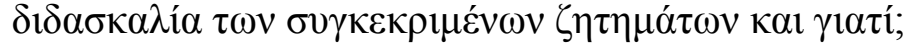

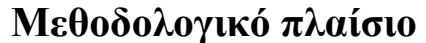

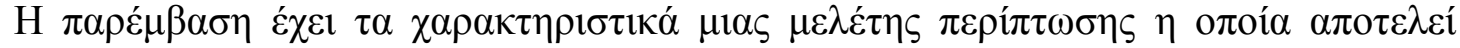

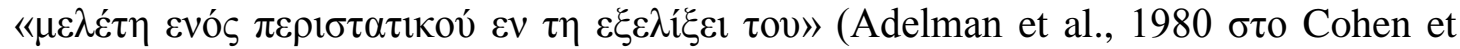

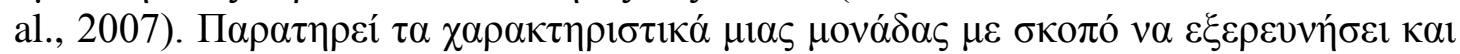

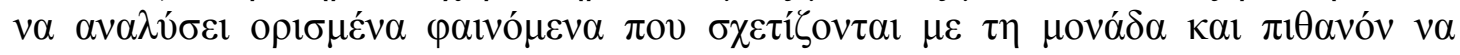

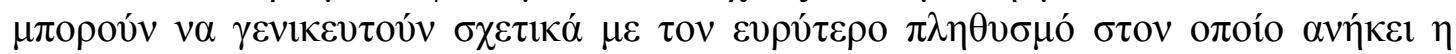

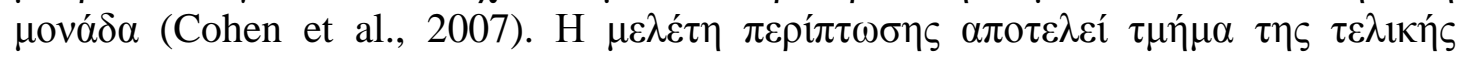

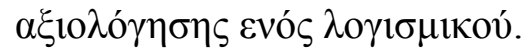

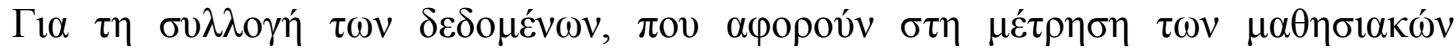

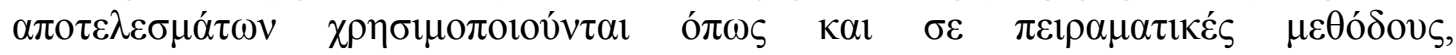

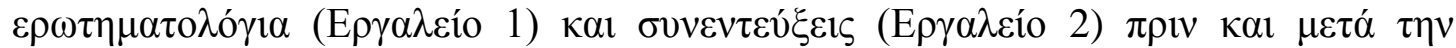
$\pi \alpha \rho \varepsilon ́ \mu \beta \alpha \sigma \eta(\Sigma o \lambda o \mu \omega v i ́ \delta o v, 2006)$.

\section{To $\delta \varepsilon i ́ r \mu \alpha$}

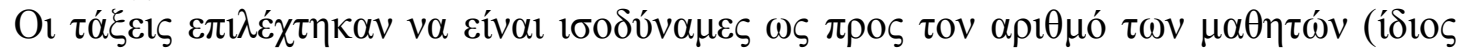

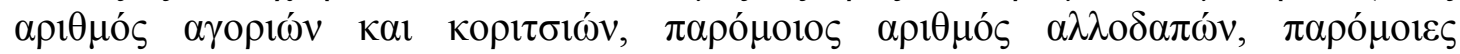

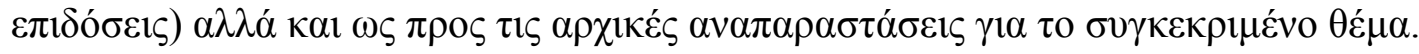

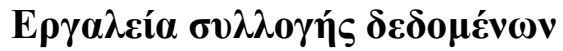

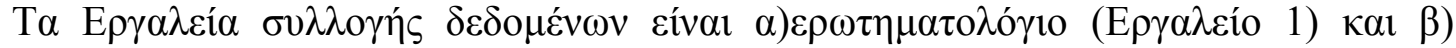

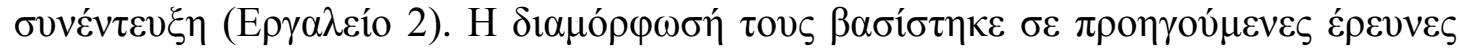

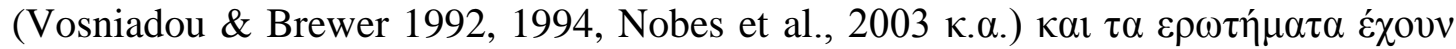

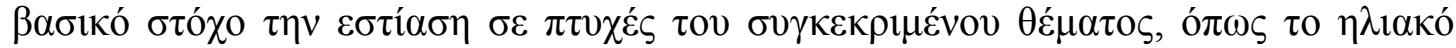

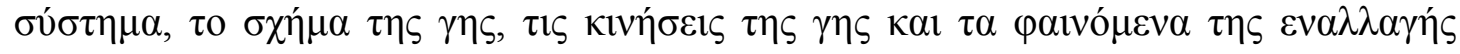

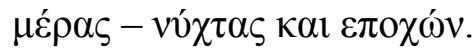

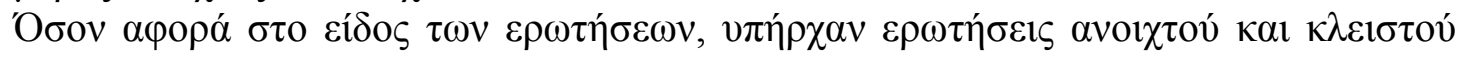

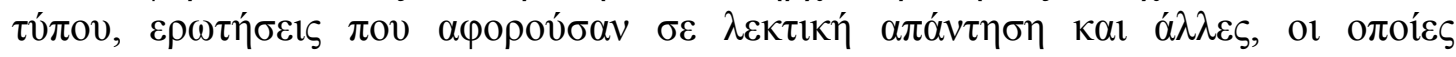

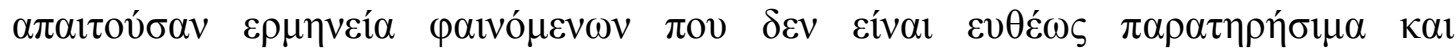

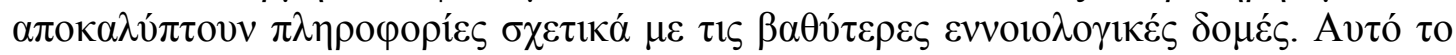

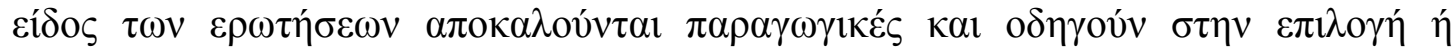

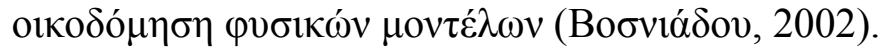

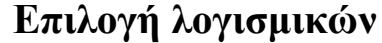

Гı

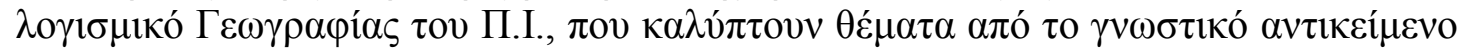

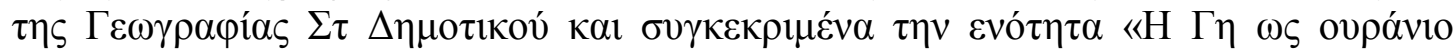

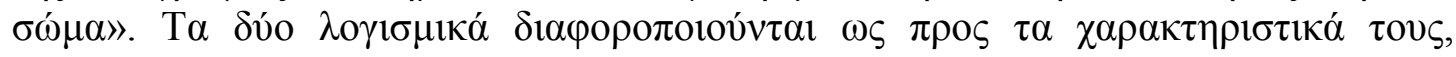

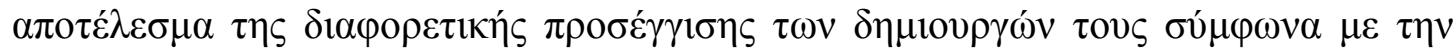

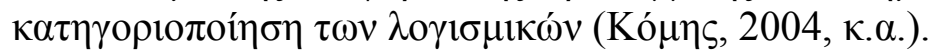

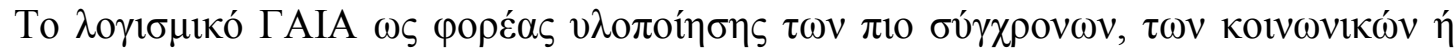

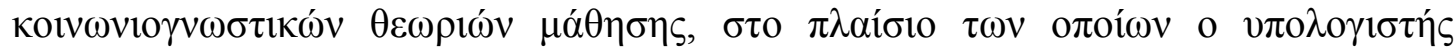

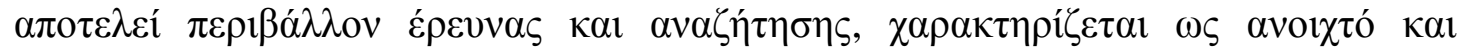

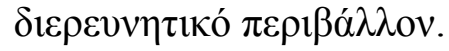




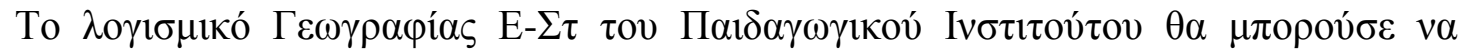

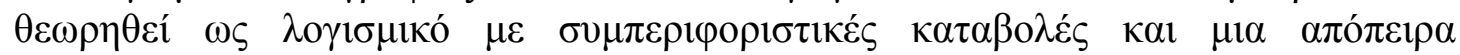

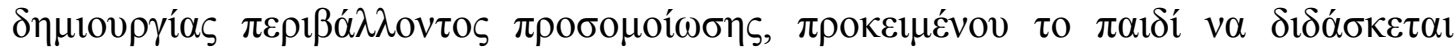

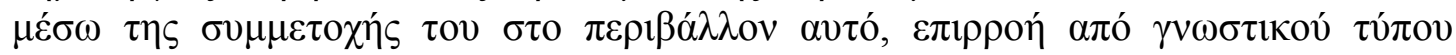

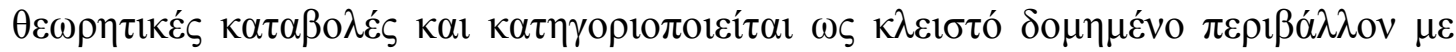

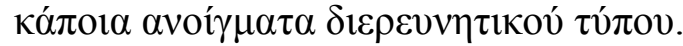

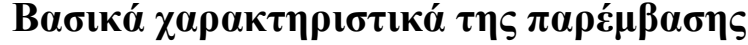

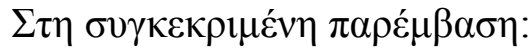

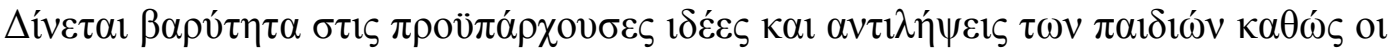

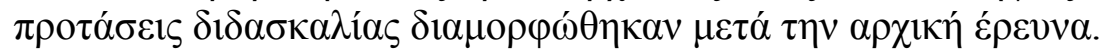

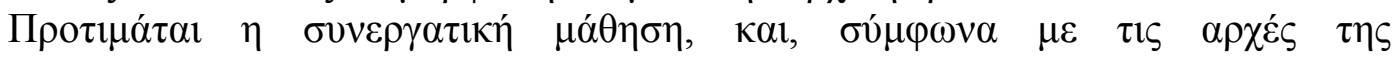

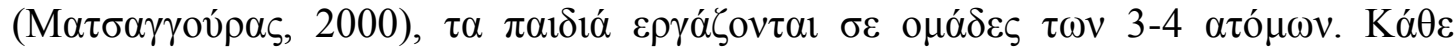

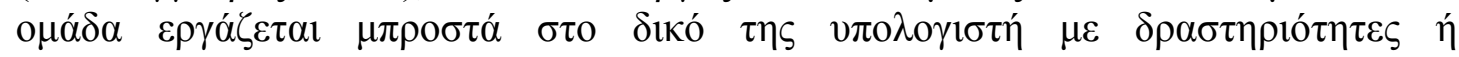

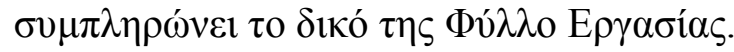

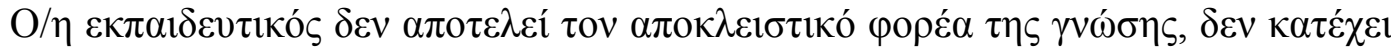

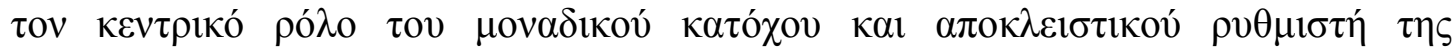

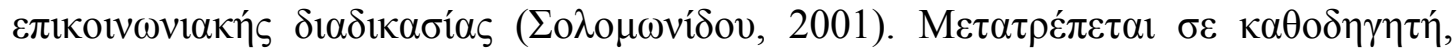

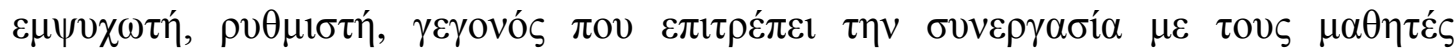

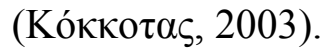

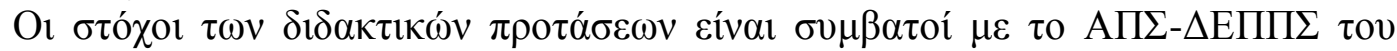

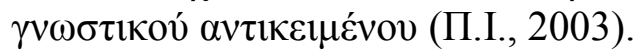

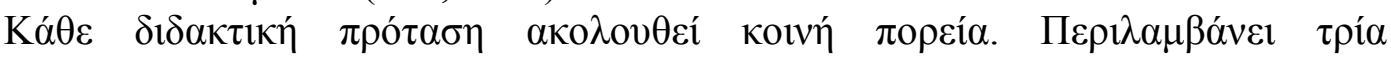

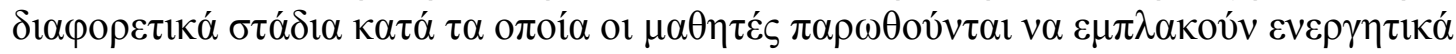

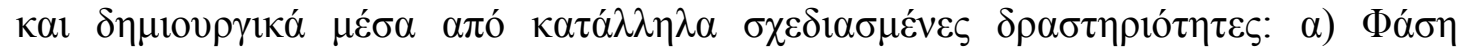

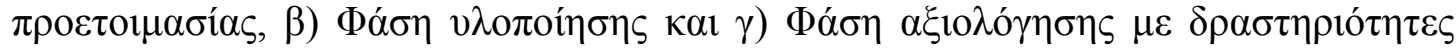

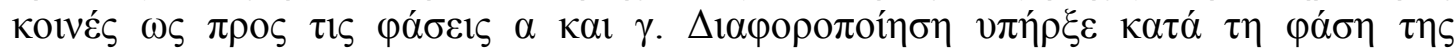

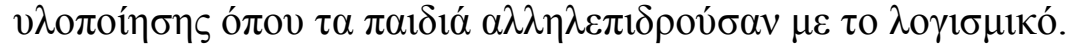

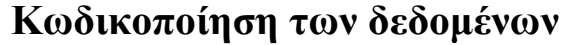

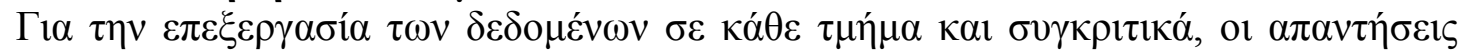

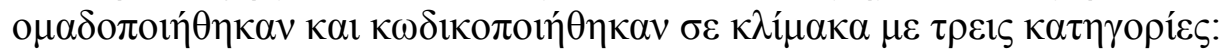

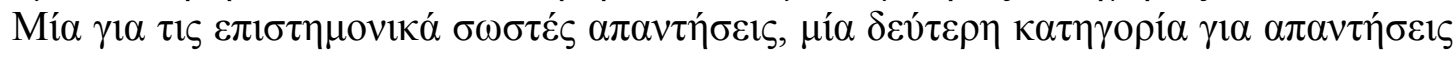

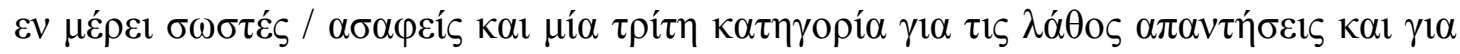

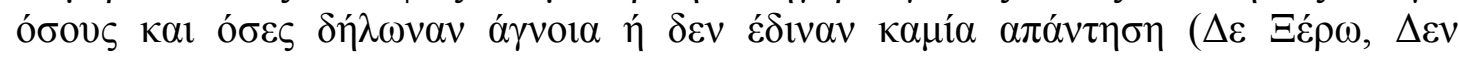
A $\pi \alpha \nu \tau \dot{)})$.

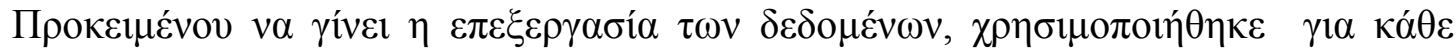

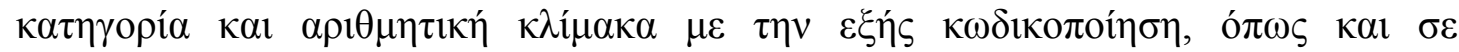

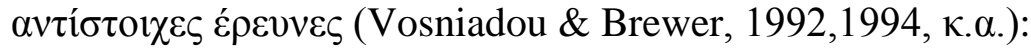

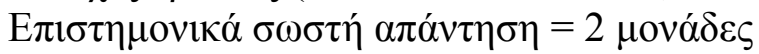

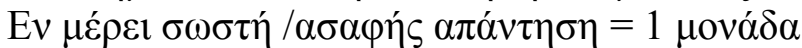

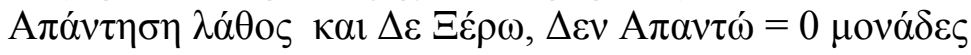

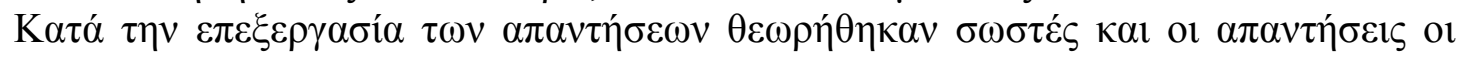

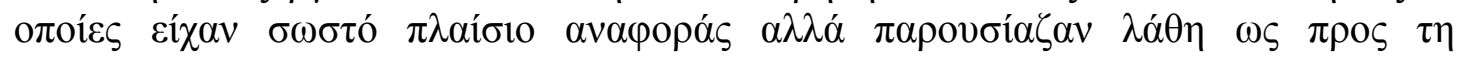
$\delta 1 \alpha \tau u ́ \pi \omega \sigma \eta$.

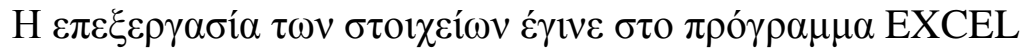

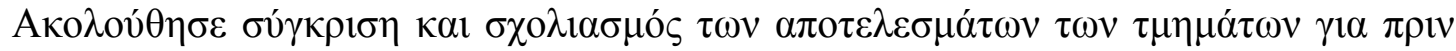

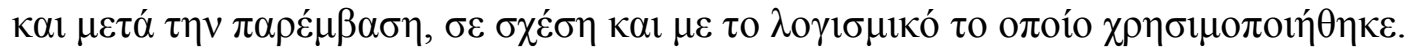

\section{E $\pi \varepsilon \xi \varepsilon \rho \gamma \alpha \sigma i ́ \alpha \tau \omega v \delta \varepsilon \delta 0 \mu \varepsilon ́ v \omega v$}




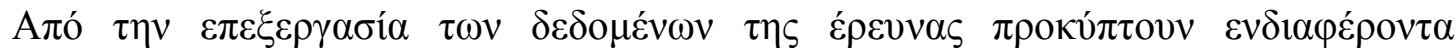

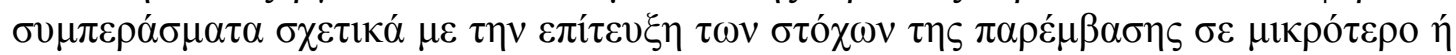

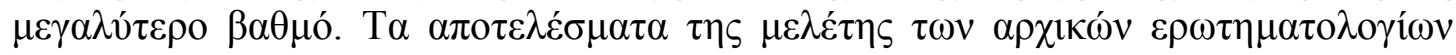

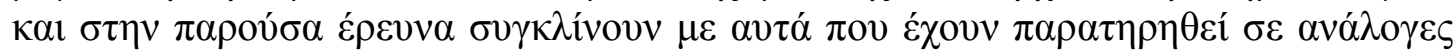

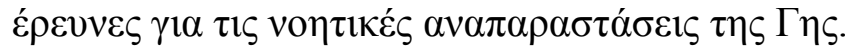

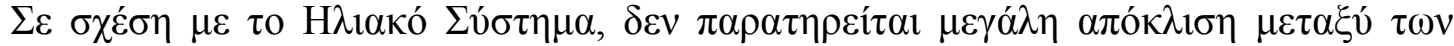

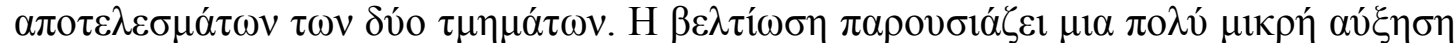

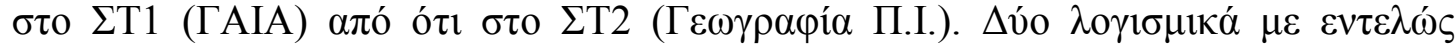

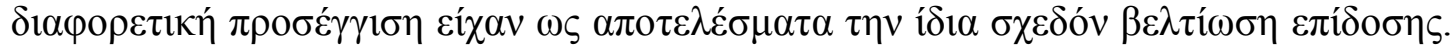

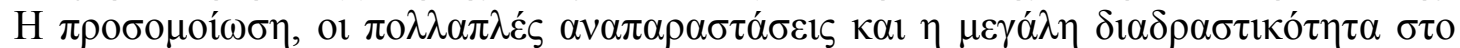

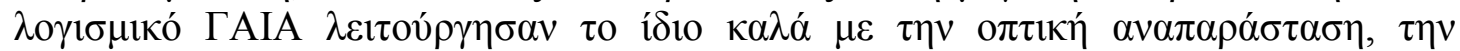

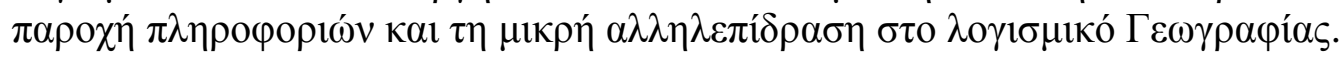

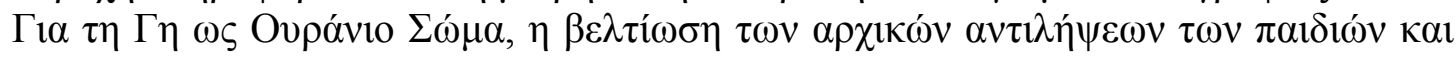

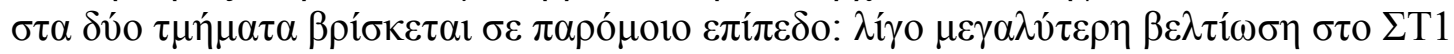

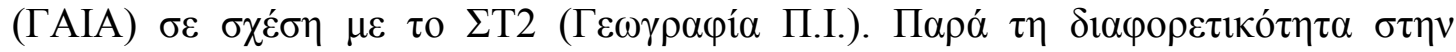

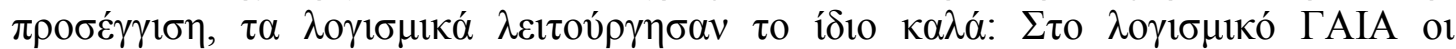

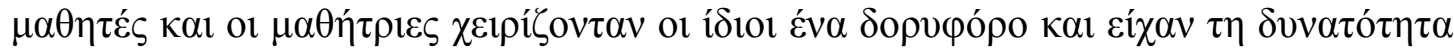

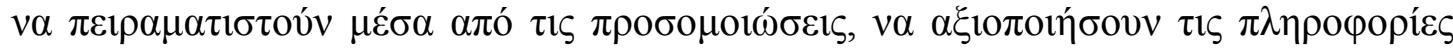

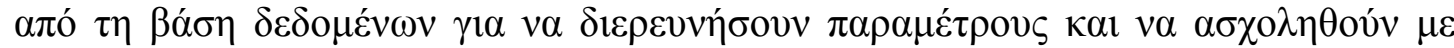

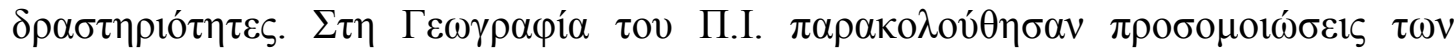

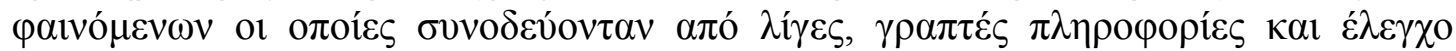

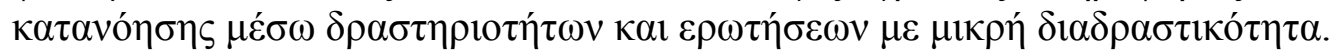

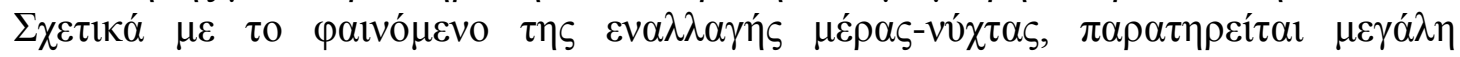

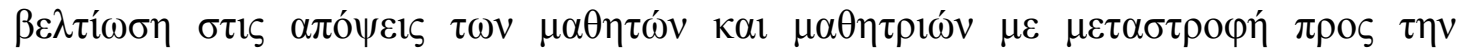

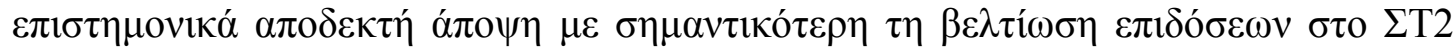

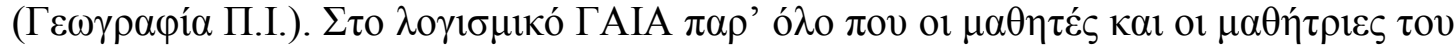

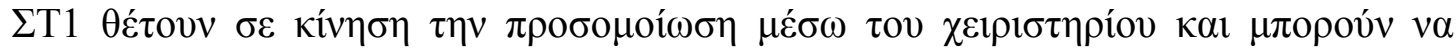

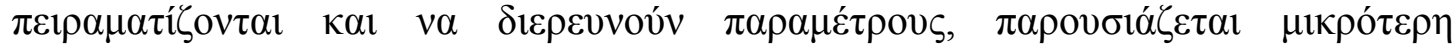

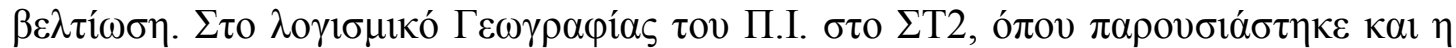

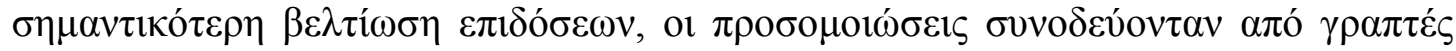

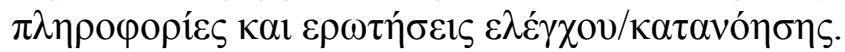

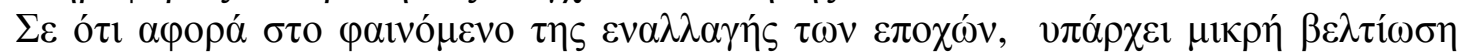

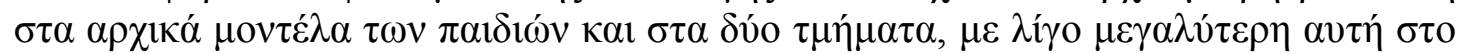

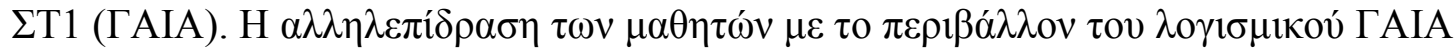

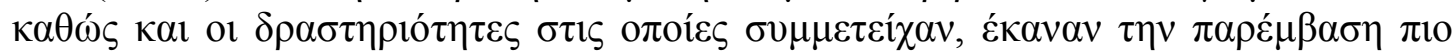

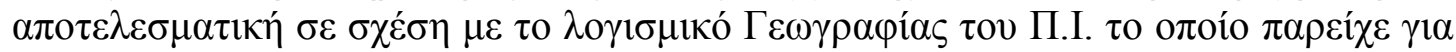

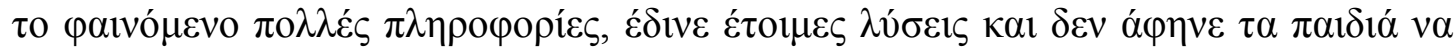
$\alpha v \tau \varepsilon v \varepsilon \rho \gamma \eta ́ \sigma o v v$.

\section{$\Sigma v \mu \pi \varepsilon \rho \alpha ́ \sigma \mu \alpha \tau \alpha$}

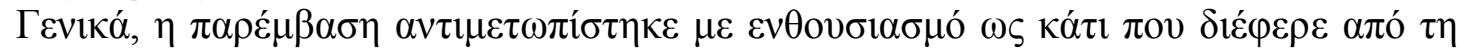

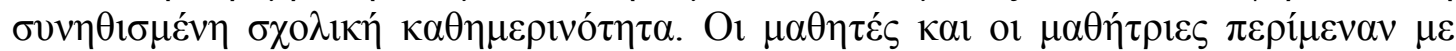

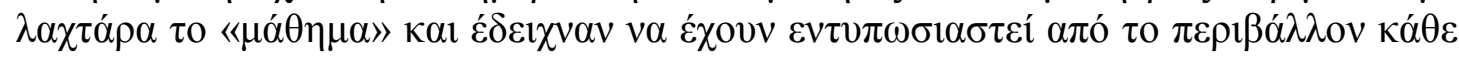

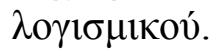

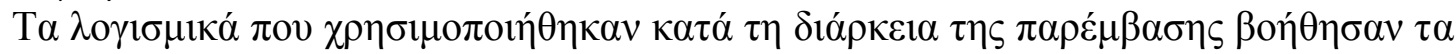

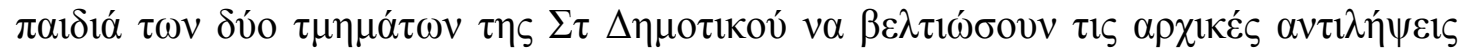

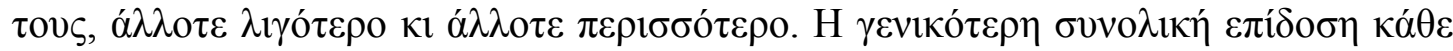

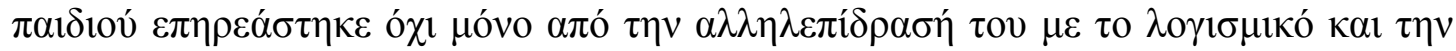

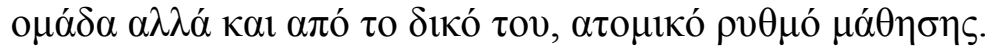




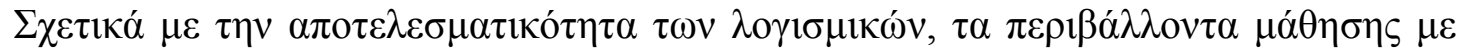

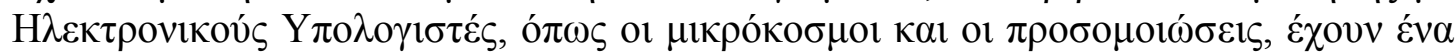

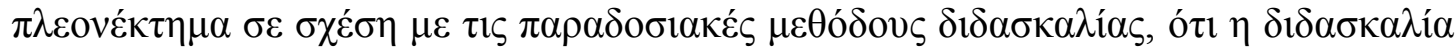

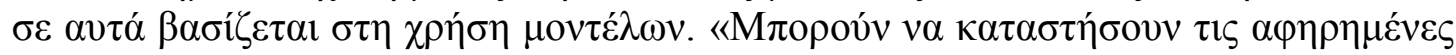

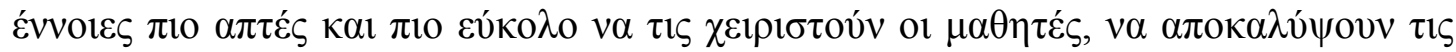

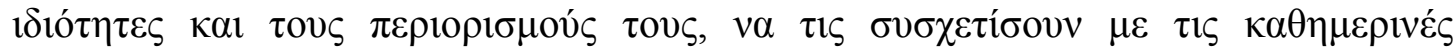

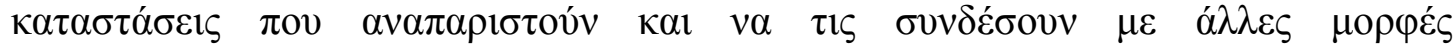

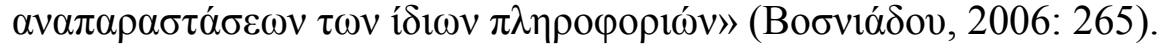

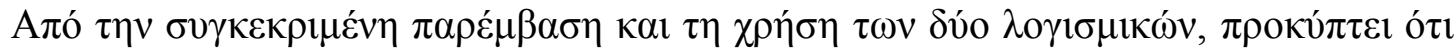

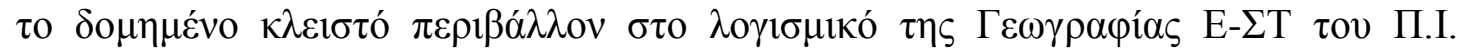

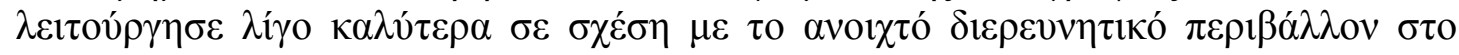

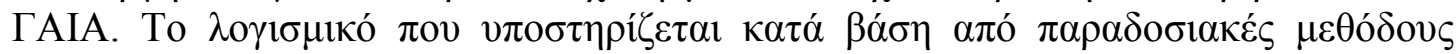

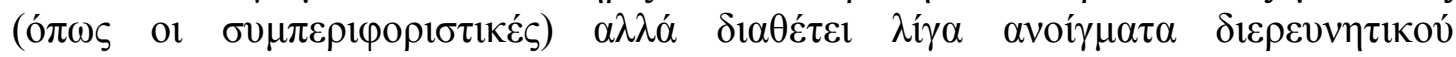

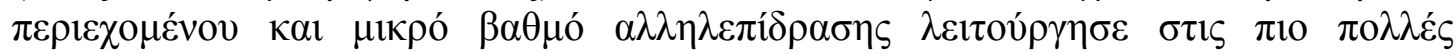

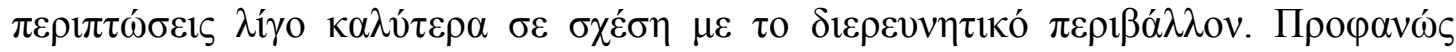

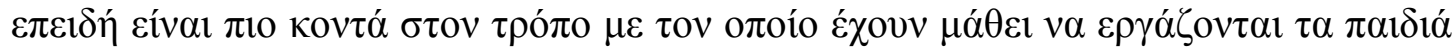

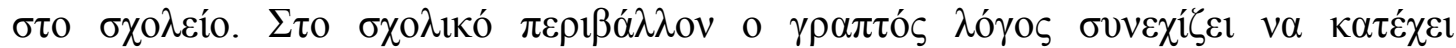

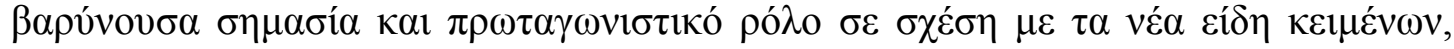

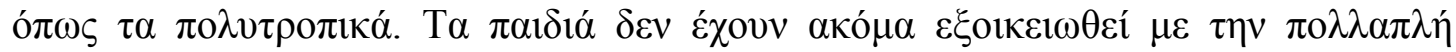

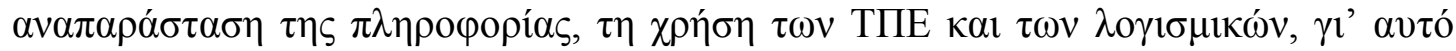

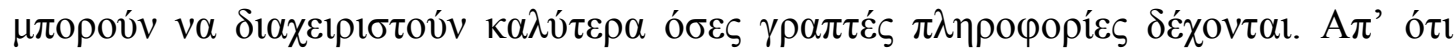

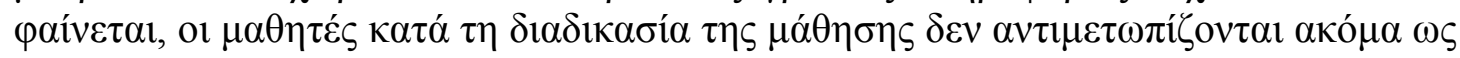

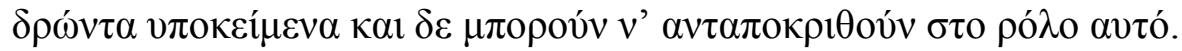

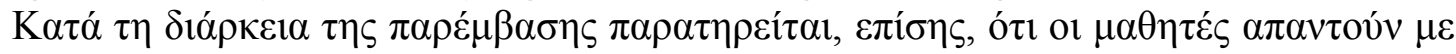

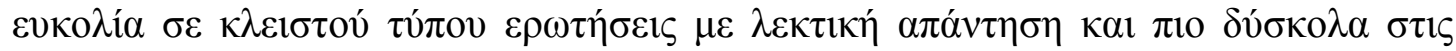

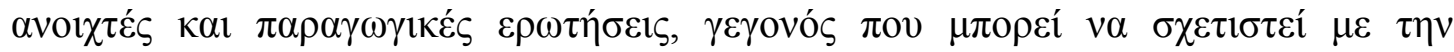

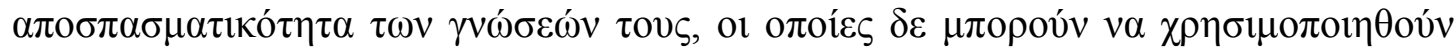

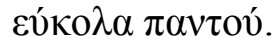

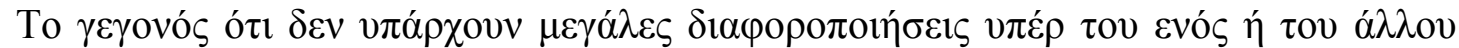

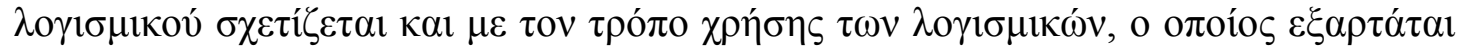

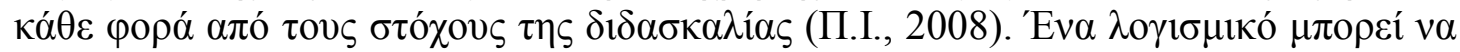

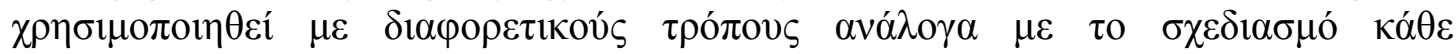

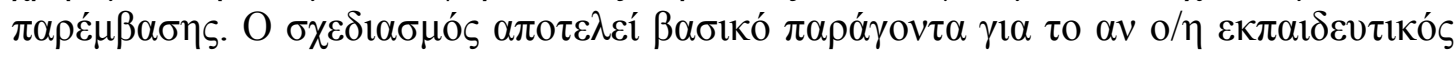

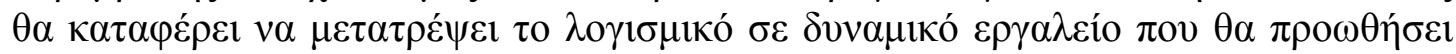

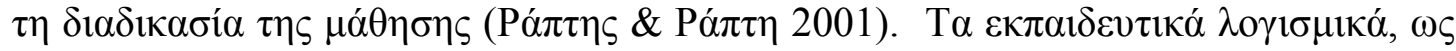

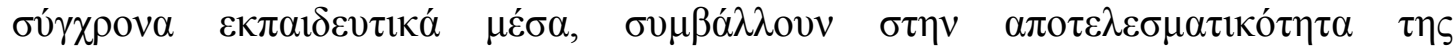

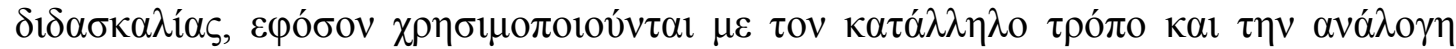

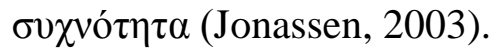

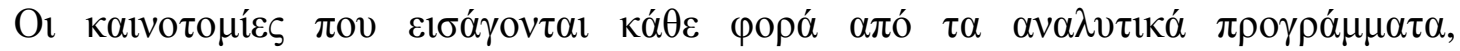

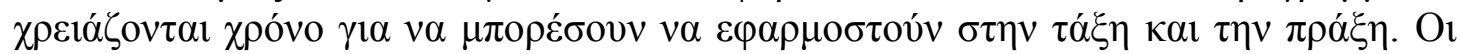

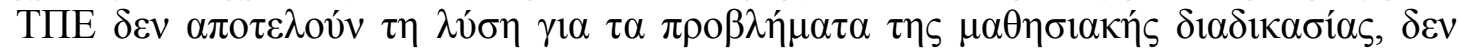

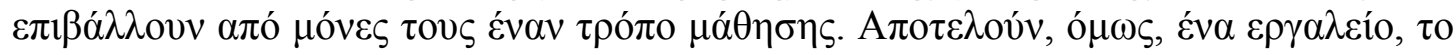

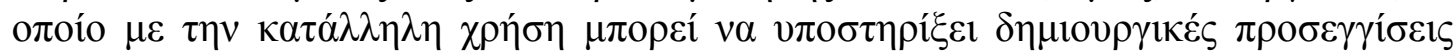

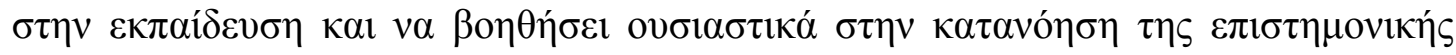

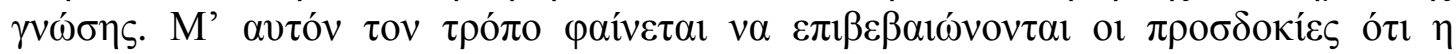

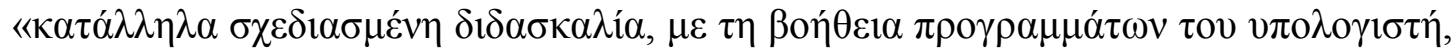

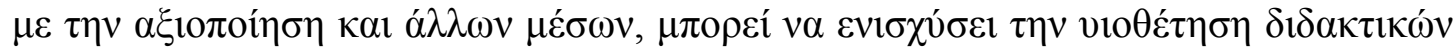

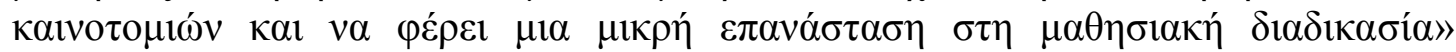

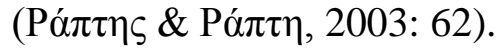




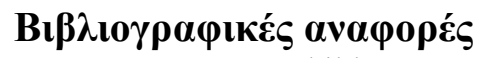

Baxter, J., (1989). Children's understanding of familiar astronomical events, International Journal of Science Education, 11 (Special Issue), p. 502

Jonassen, D. H., (2003). Computers as mind tools for schools: engaging critical thinking. NJ: PrenticeHall

Mali, G. B. \& Howe, A., (1979). Development of earth and gravity concepts among Nepali children, Science Education, p. 63

Nobes, G., Moore, D. G., Martin, A. E., Clifford, B. R., Butterworth, G., Panagiotaki, G. \& Siegal, M., (2003). Children's Understanding of the Earth in a Multicultural Community: Mental Models or Fragments of knowledge? Developmental Science, 6, p. 72

Novak, J. D., (Ed.), (1987). Proceedings of the Second International Seminar: Misconceptions and Educational Strategies in Science and Mathematics, Vol. I-III, Ithaca, NY: Comell University, Department of Education

Nussbaum, J., (1979). Children's conceptions of the earth as a cosmic body: A cross age study. Science Education, 63, p. 83

Vosniadou, S. \& Brewer, W.F., (1992). Mental Models of the Earth: a Study of Conceptual Change in Childhood, Cognitive Phsychology, 24, p. 535

Vosniadou, S. \& Brewer, W.F., (1994). Mental models of the day/night cycle. Cognitive Science, 18, p. 123

Vosniadou, S. (2001a). How children learn, Educational Practices Series, The International Academy of Education (IAE) and the International Bureau of Education (UNESCO)

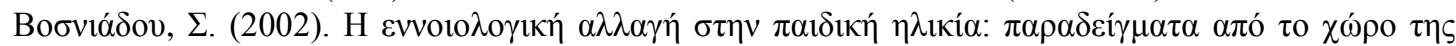

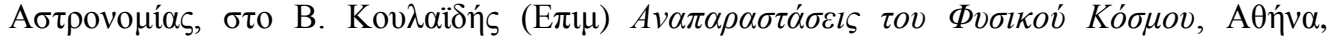

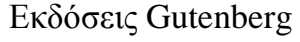

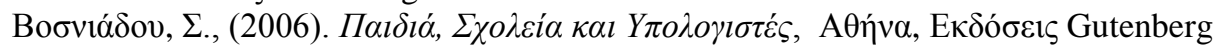

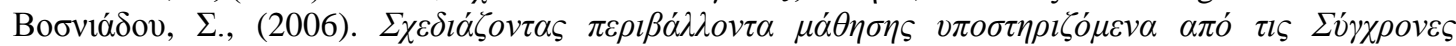

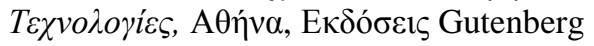

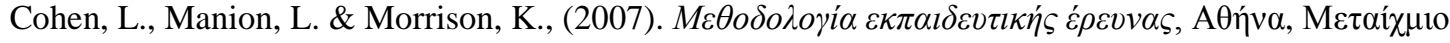

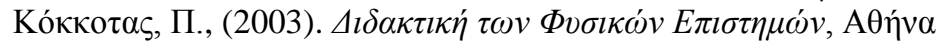

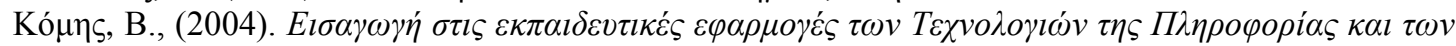

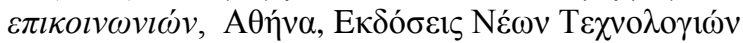

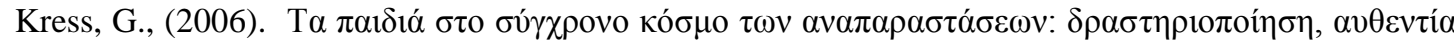

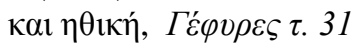

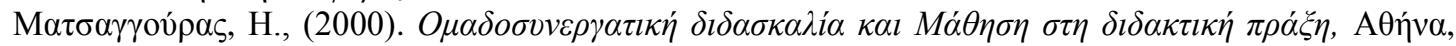

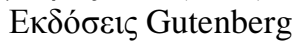

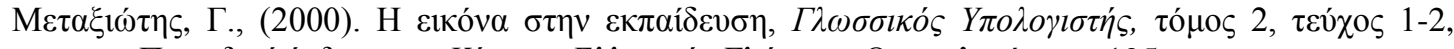

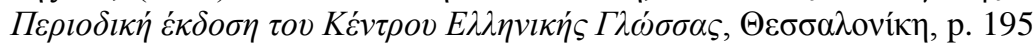

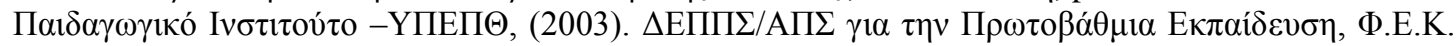
$\tau . \mathrm{B} / 303-13-3-2003$

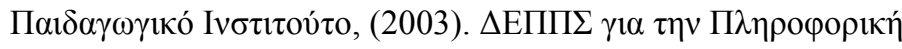

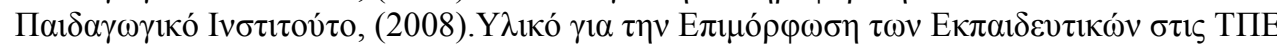

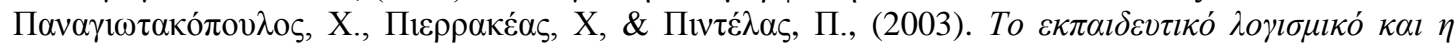

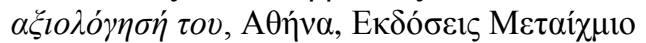

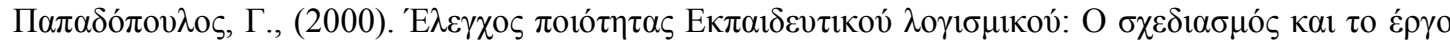

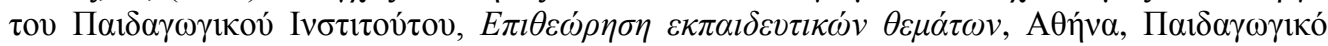

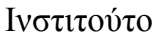

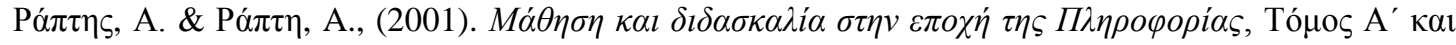

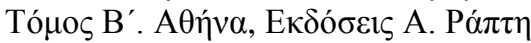

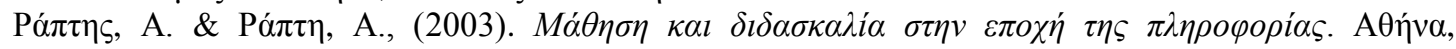

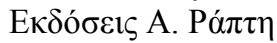

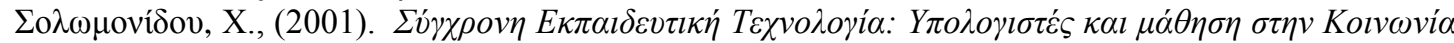

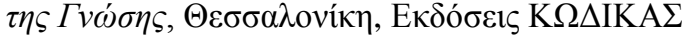

